\title{
A study on prevalence of metabolic syndrome in adult population of Ranchi
}

\author{
*Dr. Pradeep Prasad ${ }^{1}$, Dr. Mukesh Kumar Niraj ${ }^{2}$ \\ ISenior Resident, Department of Laboratory Medicine, Rajendra Institute of Medical Sciences, Ranchi. \\ 2Tutor, Department of Biochemistry, MGM College \& Hospital, Jamshedpur. \\ *Corresponding author: Dr. Pradeep Prasad
}

\begin{abstract}
:
Introduction: The Metabolic Syndrome (syndrome X, insulin resistance syndrome) consists of a constellation of metabolic abnormalities that confer increased risk of cardiovascular disease and diabetes mellitus. Coronary artery disease is the leading cause of morbidity and mortality worldwide with the heaviest toll in the developing countries.

Material and Method: The study was done in 170 subjects. The study subjects were selected randomly from patients, who were visiting the OPDs and indoors of various departments in Rajendra Institute of Medical Sciences, Ranchi

Results: It was observed that the total prevalence of metabolic syndrome is $20.6 \%$

Conclusion: The data obtained after the study shows that one out of every five adults in Ranchi is at an increased risk of developing diabetes and/or cardiovascular disease. Women are equally prone as men. Results show a shift toward a sedentary lifestyles, alcoholism and smoking.
\end{abstract}

Key Words: Metabolic Syndrome, Coronary artery disease, Diabetes Mellitus and syndrome X.

\section{Introduction}

The Metabolic Syndrome (syndrome X, insulin resistance syndrome) consists of a constellation of metabolic abnormalities that confer increased risk of cardiovascular disease and diabetes mellitus ${ }^{1}$.The metabolic syndrome is a cluster of risk factors like impaired glucose tolerance, abdominal obesity, dyslipidemia and hypertension.

Coronary artery disease is the leading cause of morbidity and mortality worldwide with the heaviest toll in the developing countries ${ }^{2}$. Recent studies show that, overall the diabetics have a two fold increase in risk of coronary heart disease ${ }^{3}$. Angiographic data on Indian patients with suspected coronary artery disease had revealed that triple vessel disease was much higher in diabetics as compared to non-diabetics to be followed by double vessel disease while single vessel disease was more common in non-diabetics ${ }^{4}$.In a recent publication from Ahmadabad there has been substantial rise in prevalence of coronary artery disease from 5.8\% to 20-30\% amongst diabetics over the period of time ${ }^{5}$.

According to statistical fact sheet given by American Heart Association (2010 update, National Health and Nutritional Examination Survey - 2003-06), the prevalence among males age 20-39 years was 20.3\%, age 40-59 years was $40.8 \%$ and age $>60$ years was $51.5 \%$, among females age 20-39 years was 15.6\%, age 40-59 years was $37.2 \%$ and age $>60$ years was $54.4 \%$. A study conducted by Cameron AJ, Shaw JE, Zimmet PZ et al (2004) shows that among US people (age 30-79 years) the prevalence was $29 \%$ among males and $32.8 \%$ among females, in English population (age 40-65 years) the prevalence 44.8\% among males and 30.9\% among females, in Iranian population (age >20 years) the prevalence was $24 \%$ among males and $42 \%$ among females, in Chennai population ( age $>20$ years) the prevalence was $36.4 \%$ among males and $46.5 \%$ females. Reddy et al conducted a multicentric study in subjects 20-69 years of age belonging to industrial employees and their families show Bangalore- 38.8\%, Trivandrum- 37.9\%, Hyderabad- 33\%, and Lucknow- 29\% (bulletin of WHO June- 2004). Gupta et al estimated the prevalence in Bhatiya community in Rajasthan; it was $36.2 \%$ among males and $47.8 \%$ among females (journal Indian Heart-2004) ${ }^{6}$. The above data indicates that the metabolic syndrome is a global problem. The situation in India is alarming too.

The concept of metabolic syndrome dates back to 1920, when Kylin ${ }^{7}$, a Swedish physician first described a constellation of metabolic disorder. In 1988, Reaven named these constellations of abnormalities as syndrome $\mathrm{X}$ and proposed insulin resistance as the underlying factor but he did not include obesity ${ }^{8}$. Further in 1998 WHO proposed its criteria on metabolic syndrome. The world has finally started accepting metabolic syndrome as a new disease entity.

Since scientists, doctors, researchers from all over the world are working seriously to find a sharply defined picture of metabolic syndrome, a large number of definitions have come into existence as, 1. WHO definition(1999) 2.European group for the study of insulin resistance(EGIR-1999) 3.The national cholesterol 
education programme- $3^{\text {rd }}$ adult treatment panel(NCEP ATPIII-2001) 4.American association of clinical endocrinology (AACE) Position statement(2002) 5.International diabetes federation definition(IDF-2004) 6.Platinum standard definition(IDF-2004).

The fundamental mechanism that leads to the metabolic syndrome still remains unknown. Many researchers have tried to put forward possible hypothesis and explanations for the mechanism that links the different component of the metabolic syndrome. Insulin resistance, leptin resistance, obesity/visceral adiposity, beta-cell dysfunction, endothelial dysfunction, sympathetic overactivity, reduced serotonergic responsivity, endocannabinoid system overactivity. Thrifty genotype and candidate genes are some of the etiological factors that have been proposed to cause metabolic syndrome. Besides these, there are multiple risk factors which are associated like advancing age, gender and sex hormone imbalance, race and ethnicity, socioeconomic status, family history of chronic disease, genetic factors, food habits and addictions, physical activity, psychological and personality factors, obstructive sleep apnea syndrome, BMI (body mass index) and waist circumference etc. In last few decades world has changed rapidly. A fast pace of life, affluence, lack of time has greatly affected the urban population leading to major changes in life style and food habits. There has been a dietary transition from a high fibre complex carbohydrate diet to a low fibre refined carbohydrate diet. Above all an increasingly sedentary lifestyle combined with professional stress has lead to emergence of large number of risk factors for various diseases. Metabolic syndrome is very important disease related to these sudden changes in life style and food habits.

Knowing the importance of metabolic syndrome several studies being carried out worldwide. Recent studies show prevalence in USA is about $25 \%$ of the adult population (survey JAMA-287, $3^{\text {rd }}$ National Health and Nutritional Examination Survey or NHANES-11l).In India Mishra A et al on north Indian population (Delhi), Gupta $\mathrm{R}$ et al on Punjabi Bhatia community (Jaipur) and Deepa $\mathrm{R}$ et al on urban population of Chennai did extensive study. The results of the above studies are alarming. There is a great need of a similar study in Ranchi, capital city of newly formed state Jharkhand. Ranchi of late very fastly being influenced by westernization in life style and diet, and thus it was selected for the present study. The outcomes of the present study will hopefully help in evaluating current situation, so that effective preventive and treatment strategies could be deployed.

\section{Materials And Methodology}

The study was done in 170 subjects. The study subjects were selected randomly from patients, who were visiting the OPDs and indoors of various departments like department of Medicine, Surgery, Obstetrics and Gynaecology, ENT, Eye .Medical students, Para-medical staffs and local population of Ranchi were also taken as a study subjects.

\section{Inclusion criteria}

1. Age18-60 years both the sexes

2. Should be fasting for at least 10 hours and should readily agree to participate in the study with an informed consent.

\section{Exclusion criteria}

1. Non-cooperative patients

2. Patients suffering from serious illness which might affect biochemical parameters like chronic liver disease, renal disease, AIDS, chronic psychiatric illness.

\section{Results}

Statistical Analysis: The data was analyzed by using SPSS 20 software. The data is presented in percentages, rates and ratios. Chi square test was used to find the association between attributes.

Table - I: Age Distribution

\begin{tabular}{|c|c|c|}
\hline \multicolumn{3}{|c|}{ Distribution of study population according to age } \\
\hline Age group & Number of subjects & Percentage \\
\hline $18-30$ years & 50 & 29.4 \\
\hline $31-40$ years & 66 & 38.8 \\
\hline $41-50$ years & 35 & 20.6 \\
\hline $51-60$ years & 19 & 11.2 \\
\hline Total & 170 & 100.0 \\
\hline
\end{tabular}

Table - I shows majority, 66 (38.8\%) subjects belong to 31-40 years age group. 50 (29.4\%) subjects belong to 21-30 years, $35(20.6 \%)$ subjects belong to $41-50$ years and $19(11.2 \%)$ subjects belong to 51-60 years age group. 
Table - II: Sex distribution

\begin{tabular}{|c|c|c|}
\hline \multicolumn{3}{|c|}{ Distribution of study population according to sex } \\
\hline Sex & Number of subjects & Percentage \\
\hline Male & 96 & 56.5 \\
\hline Female & 74 & 43.5 \\
\hline Total & 170 & 100.0 \\
\hline
\end{tabular}

The above table shows that 96 (56.5\%) subjects are male and 74 (43.5\%) subjects are female.

Table - III: Family history of different disease

\begin{tabular}{|c|c|c|}
\hline \multicolumn{2}{|c|}{ Distribution of study population according to family history of different disease } \\
\hline & Number of subjects & \multicolumn{2}{c|}{ Percentage } \\
\hline No family history (N) & 111 & 65.3 \\
\hline Hypertension (H) & 11 & 6.5 \\
\hline Hypertension \& Diabetes (HD) & 10 & 5.9 \\
\hline Hypertension, Diabetes \& Obesity (HDO) & 3 & 1.8 \\
\hline Hypertension \& Obesity & 7 & 4.2 \\
\hline Diabetes (D) & 18 & 10.6 \\
\hline Obesity (O) & 2 & 1.2 \\
\hline Obesity \&Diabetes (OD) & 8 & \\
\hline Total & 170 & 100.0 \\
\hline
\end{tabular}

The above data shows that majority of study population that is $111(63.5 \%)$ didn't report history of any family diseases.

$18(10.6 \%)$ subjects had a family history of Diabetes (D), $11(6.5 \%)$ subjects had a family history of Hypertension (H), $10(5.9 \%)$ subjects had a family history of Hypertension and Diabetes (HD), 7 (4.2\%) subjects had a family history of Hypertension and Obesity (HO), $8(4.5 \%)$ subjects had a family history of Obesity and Diabetes (OD), 3 (1.8\%) subjects had a family history of Hypertension, Diabetes and Obesity (HDO) and $2(1.2 \%)$ subjects had a family history of Obesity (O).

Table - IV: Addiction

\begin{tabular}{|c|c|c|}
\hline \multicolumn{2}{|c|}{ Distribution of study population according to Addiction } & Percentage \\
\hline Addiction & Number of subjects & 9.4 \\
\hline Smoking & 16 & 1.2 \\
\hline Smoking \& Alcoholism & 02 & 5.3 \\
\hline Smoking, tobacco and alcoholism & 09 & 19.4 \\
\hline Chewing Tobacco & 33 & 0.6 \\
\hline Chewing Tobacco and Alcoholism & 01 & 4.7 \\
\hline Tobacco and Smoking & 08 & 59.4 \\
\hline No addiction & 101 & 100.0 \\
\hline Total & 170 & \\
\hline
\end{tabular}

The above data shows 101 (59.4\%) subjects didn't had any addiction. 33 (19.4\%) subjects were addicted to Chewing tobacco, $16(9.4 \%)$ subjects were addicted to Smoking, $9(5.3 \%)$ subjects were addicted to Chewing tobacco, Smoking and Alcoholism, 8 (4.7\%) subjects were addicted to Chewing tobacco and Smoking, 2 (1.2\%) subjects were addicted to Smoking and Alcoholism and $1(0.6 \%)$ subjects were addicted to Chewing tobacco and Alcoholism.

Table - V: Life style

\begin{tabular}{|c|c|c|}
\hline \multicolumn{3}{|c|}{ Distribution of study population according to Life style } \\
\hline Life styles & Number of subjects & percentage \\
\hline Active & 32 & 18.8 \\
\hline Moderately active & 94 & 55.3 \\
\hline Sedentary & 44 & 25.9 \\
\hline Total & 170 & 100.0 \\
\hline
\end{tabular}

The above data shows, 94 (55.3\%) subjects had Moderately active life style, 44 (25.9\%) subjects had Sedentary life style and $32(18.8 \%)$ had Active life style.
DOI: $10.9790 / 0853-1607017277$
www.iosrjournals.org
$74 \mid$ Page 
Table - VI: Prevalence (\%) of Hypertension in study population

\begin{tabular}{|c|c|c|c|c|c|c|c|c|c|}
\hline \multicolumn{8}{|c|}{ Prevalence (\%) of Hypertension in study population } \\
\hline & \multicolumn{3}{|c|}{ Hypertension } & \multicolumn{3}{c|}{ Normal } & \multicolumn{3}{c|}{ Total } \\
\hline & $\mathrm{M}$ & $\mathrm{F}$ & $\mathrm{T}$ & $\mathrm{M}$ & $\mathrm{F}$ & $\mathrm{T}$ & $\mathrm{M}$ & $\mathrm{F}$ & $\mathrm{T}$ \\
\hline Number of subjects & 28 & 17 & 45 & 68 & 57 & 125 & 96 & 74 & 170 \\
\hline $\begin{array}{c}\text { \% within } \\
\text { corresponding } \\
\text { Hypertension }\end{array}$ & $62.2 \%$ & $37.8 \%$ & $100.0 \%$ & $54.4 \%$ & $45.6 \%$ & $100.0 \%$ & $56.5 \%$ & $43.5 \%$ & $100.0 \%$ \\
\hline \% within sex & $29.2 \%$ & $23.0 \%$ & $26.5 \%$ & $70.8 \%$ & $77.0 \%$ & $73.5 \%$ & $100.0 \%$ & $100.0 \%$ & $100.0 \%$ \\
\hline \% of Total & $16.5 \%$ & $10.0 \%$ & $26.5 \%$ & $40.0 \%$ & $33.5 \%$ & $73.5 \%$ & $56.5 \%$ & $43.5 \%$ & $100.0 \%$ \\
\hline \multicolumn{7}{|c|}{$\mathrm{M}=$ Male, F= Female, T= Total ${ }_{x}{ }^{2}=0.37, \mathrm{p}=0.54$} \\
\hline
\end{tabular}

In the present study Blood pressure > 130/85 mmHg was taken as Hypertension. 45 (26.5\%) subjects were Hypertensive. Among Hypertensive 28 (16.5\%) were males and 17 (10.0\%) were females.

Table - VII: Prevalence (\%) of Overweight and Obesity in study population

\begin{tabular}{|c|c|c|c|c|c|c|c|c|c|c|c|c|}
\hline \multicolumn{13}{|c|}{ Prevalence (\%) of Overweight and Obesity in study population } \\
\hline & \multicolumn{3}{|c|}{ Normal } & \multicolumn{3}{|c|}{ Overweight } & \multicolumn{3}{|c|}{ Obese } & \multicolumn{3}{|c|}{ Total } \\
\hline & $\mathrm{M}$ & $\mathrm{F}$ & $\mathrm{T}$ & $\mathrm{M}$ & $\mathrm{F}$ & $\mathrm{T}$ & $\mathrm{M}$ & $\mathrm{F}$ & $\mathrm{T}$ & $\mathrm{M}$ & $\mathrm{F}$ & $\mathrm{T}$ \\
\hline Number of subjects & 59 & 47 & 106 & 28 & 20 & 48 & 9 & 7 & 16 & 96 & 74 & 170 \\
\hline$\%$ within sex & $\begin{array}{c}61.4 \\
\%\end{array}$ & $\begin{array}{c}63.5 \\
\%\end{array}$ & $\begin{array}{c}62.2 \\
\%\end{array}$ & $\begin{array}{c}29.1 \\
\%\end{array}$ & $\begin{array}{c}27.0 \\
\%\end{array}$ & $\begin{array}{c}28.2 \\
\%\end{array}$ & $\begin{array}{c}9.3 \\
\%\end{array}$ & $\begin{array}{c}9.4 \\
\%\end{array}$ & $\begin{array}{c}9.4 \\
\%\end{array}$ & - & - & - \\
\hline $\begin{array}{c}\text { \% within } \\
\text { corresponding BMI } \\
\text { group }\end{array}$ & $\begin{array}{c}55.7 \\
\%\end{array}$ & $\begin{array}{c}44.3 \\
\%\end{array}$ & $\begin{array}{c}100.0 \\
\%\end{array}$ & $\begin{array}{c}58.3 \\
\%\end{array}$ & $\begin{array}{c}41.7 \\
\%\end{array}$ & $\begin{array}{c}100.0 \\
\%\end{array}$ & $\begin{array}{c}56.3 \\
\%\end{array}$ & $\begin{array}{c}43.7 \\
\%\end{array}$ & $\begin{array}{c}100.0 \\
\%\end{array}$ & $\begin{array}{c}56.5 \\
\%\end{array}$ & $\begin{array}{c}43.5 \\
\%\end{array}$ & $\begin{array}{c}100.0 \\
\%\end{array}$ \\
\hline$\%$ of Total & $\begin{array}{c}34.7 \\
\%\end{array}$ & $27.6 \%$ & $62.3 \%$ & $16.5 \%$ & $11.8 \%$ & $\begin{array}{c}28.3 \\
\%\end{array}$ & $\begin{array}{c}5.3 \\
\%\end{array}$ & $\begin{array}{c}4.1 \\
\%\end{array}$ & $\begin{array}{c}9.4 \\
\%\end{array}$ & $\begin{array}{c}56.5 \\
\%\end{array}$ & $43.5 \%$ & $100.0 \%$ \\
\hline
\end{tabular}

The above data shows that $106(62.3 \%)$ subjects were Normal. $16(9.4 \%)$ subjects were Obese and $48(28.3 \%)$ subjects were Overweight. Among females the prevalence of Obesity was $9.4 \%$ and Overweight was $27.0 \%$. Among males prevalence of Obesity was $9.3 \%$ and Overweight was $29.1 \%$.

Table - VIII: Prevalence (\%) of Impaired Glucose Tolerance in study population

\begin{tabular}{|c|c|c|c|c|c|c|c|c|c|}
\hline \multicolumn{10}{|c|}{ Prevalence (\%) of Impaired Glucose Tolerance in study population } \\
\hline & \multicolumn{3}{|c|}{$\begin{array}{l}\text { Normal Fasting Plasma } \\
\text { Glucose }(<110 \mathrm{mg} / \mathrm{dl})\end{array}$} & \multicolumn{3}{|c|}{$\begin{array}{c}\text { Impaired Glucose Tolerance }(\geq 110 \\
\mathrm{mg} / \mathrm{dl})\end{array}$} & \multicolumn{3}{|c|}{ Total } \\
\hline & $\mathrm{M}$ & $\mathrm{F}$ & $\mathrm{T}$ & $\mathrm{M}$ & $\mathrm{F}$ & $\mathrm{T}$ & $\mathrm{M}$ & F & $\mathrm{T}$ \\
\hline $\begin{array}{l}\text { Number of } \\
\text { subjects }\end{array}$ & 72 & 57 & 129 & 24 & 17 & 41 & 96 & 74 & 170 \\
\hline$\%$ within FPG & $55.8 \%$ & $44.2 \%$ & $100.0 \%$ & $58.5 \%$ & $41.5 \%$ & $100.0 \%$ & $56.5 \%$ & $43.5 \%$ & $100.0 \%$ \\
\hline$\%$ within sex & $75.0 \%$ & $77.0 \%$ & $75.9 \%$ & $25.0 \%$ & $23.0 \%$ & $24.1 \%$ & $100.0 \%$ & $100.0 \%$ & $100.0 \%$ \\
\hline$\%$ of Total & $42.3 \%$ & $33.5 \%$ & $75.9 \%$ & $14.1 \%$ & $10.0 \%$ & $24.1 \%$ & $56.5 \%$ & $43.5 \%$ & $100.0 \%$ \\
\hline & & & $\mathrm{PG}-\mathrm{Fa}$ & $\overline{\text { Plasma }}$ & $\mathrm{ose},{ }^{2}=$ & $\mathrm{p}=0.51$ & & & \\
\hline
\end{tabular}

The above data shows that most of the study population had normal Fasting Plasma Glucose. 41 (24.1\%) subjects had Impaired Glucose Tolerance. The prevalence of Impaired Glucose Tolerance among male is $25.0 \%$ and among female is $23.0 \%$.

Table - IX: Prevalence (\%) of Hypercholesterolemia in study population

\begin{tabular}{|c|c|c|c|c|c|c|c|c|c|}
\hline \multicolumn{8}{|c|}{ Prevalence (\%) of Hypercholesterolemia in study population } \\
\hline & Total Cholesterol $<250 \mathrm{mg} / \mathrm{dl}$ & \multicolumn{2}{c|}{ Total Cholesterol $\geq 250 \mathrm{mg} / \mathrm{dl}$} & \multicolumn{3}{c|}{ Total } \\
\hline & $\mathrm{M}$ & $\mathrm{F}$ & $\mathrm{T}$ & $\mathrm{M}$ & $\mathrm{F}$ & $\mathrm{T}$ & $\mathrm{M}$ & $\mathrm{F}$ & $\mathrm{T}$ \\
\hline Number of subjects & 79 & 70 & 149 & 17 & 04 & 21 & 96 & 74 & 170 \\
\hline$\%$ within TC & $53.1 \%$ & $46.9 \%$ & $100.0 \%$ & $80.9 \%$ & $19.1 \%$ & $100.0 \%$ & $56.5 \%$ & $43.5 \%$ & $100.0 \%$ \\
\hline \% within sex & $82.3 \%$ & $94.6 \%$ & $87.6 \%$ & $17.7 \%$ & $5.4 \%$ & $12.4 \%$ & $100.0 \%$ & $100.0 \%$ & $100.0 \%$ \\
\hline \% 0f Total & $46.5 \%$ & $41.2 \%$ & $87.6 \%$ & $10.0 \%$ & $2.4 \%$ & $12.4 \%$ & $56.5 \%$ & $43.5 \%$ & $100.0 \%$ \\
\hline \multicolumn{8}{|c|}{$\mathrm{TC}=$ Total Cholesterol, ${ }_{\mathrm{x}}{ }^{2}=1.39, \mathrm{p}=0.24$} \\
\hline
\end{tabular}


The above data shows that the prevalence of total Cholesterol level $\geq 250 \mathrm{mg} / \mathrm{dl}$ is $12.4 \% .7(10.0 \%$ of total) males and $4(2.4 \%$ of total $)$ females had total cholesterol level $\geq 250 \mathrm{mg} / \mathrm{dl} .79(46.5 \%$ of total $)$ males and 70 (41.2\% of total) had total cholesterol level less than $250 \mathrm{mg} / \mathrm{dl}$.

Table - X: Prevalence (\%) of Metabolic Syndrome among both Sexes in the study population

\begin{tabular}{|c|c|c|c|c|c|c|c|c|c|}
\hline \multicolumn{10}{|c|}{ Prevalence (\%) of Metabolic Syndrome among both Sexes in the study population } \\
\hline & \multicolumn{3}{|c|}{ Female } & \multicolumn{3}{|c|}{ Male } & \multicolumn{3}{|c|}{ Total } \\
\hline & \multicolumn{3}{|c|}{ Metabolic syndrome } & \multicolumn{3}{|c|}{ Metabolic syndrome } & \multicolumn{3}{|c|}{ Metabolic syndrome } \\
\hline & $\mathrm{N}$ & $\mathrm{Y}$ & $\mathrm{T}$ & $\mathrm{N}$ & $\mathrm{Y}$ & $\mathrm{T}$ & $\mathrm{N}$ & $\mathrm{Y}$ & $\mathrm{T}$ \\
\hline Number of subjects & 57 & 17 & 74 & 78 & 18 & 96 & 135 & 35 & 170 \\
\hline$\%$ within sex & $77.0 \%$ & $23.0 \%$ & $100.0 \%$ & $81.2 \%$ & $18.8 \%$ & $100.0 \%$ & $79.4 \%$ & $20.6 \%$ & $100.0 \%$ \\
\hline $\begin{array}{l}\text { Corresponding \% } \\
\text { within cases or non- } \\
\text { cases of metabolic } \\
\text { syndrome }\end{array}$ & $42.2 \%$ & $48.6 \%$ & - & $57.8 \%$ & $51.4 \%$ & - & $100.0 \%$ & $100.0 \%$ & $100.0 \%$ \\
\hline$\%$ of Total & $33.5 \%$ & $10.0 \%$ & - & $45.9 \%$ & $10.6 \%$ & - & $79.4 \%$ & $20.6 \%$ & $100.0 \%$ \\
\hline
\end{tabular}

The above data shows the prevalence of metabolic syndrome. The total prevalence of metabolic syndrome is $20.6 \%$ that is 35 out of 170 study subjects were diagnosed as the cases of metabolic syndrome. Prevalence among females was $23.0 \%$ and among male was $18.8 \%$.

\section{Discussion}

Metabolic syndrome is widely prevalent and multi-factorial disorder. It is basically, a constellation of dyslipidemia (hypertriglyceridemia), low level of high density lipoproteins, elevated blood pressure, impaired glucose tolerance and central obesity.

A total of 170 subjects participated in the present study. This included 96(56.5\%) males and 74(43.5\%) females. The study age group was 18-60 years. Majority of subjects ,66(33.8\%) belonged to 31-40 years age group. 50 (29.4\%) subjects belonged to 21-30 years, 35(20.6\%) subjects belonged to 41-50 years and 19(11.2\%) belonged to 51-60 years age group.

The prevalence of obesity in the study population is $9.4 \%$ (16/170). Prevalence of overweight is 28.3 $\%$ (48/170). Among females prevalence of obesity is $9.4 \%$ and prevalence of overweight is $27 \%$. Prevalence of obesity among male is $9.3 \%$ and overweight is $29.1 \%$. The prevalence of obesity found in Ranchi is lower than that in Jaipur and Chennai. Ramachandran et al (2003) calculated the obesity prevalence $31 \%$ in Chennai. He used the waist-circumference that is appropriate to Indian population. In Jaipur, Gupta et al (2003) used the standard ATP III definition of obesity and found the prevalence of obesity was $33 \%$. The data obtained from the present study shows that the prevalence of obesity in Ranchi is lower than the other cities. This lower prevalence of obesity did not co-relate well with the prevalence of other risk factors which showed a higher prevalence. This is in agreement with the findings of Anoop Mishra et al (2002), which suggested that the existing definition of obesity was not appropriate for Asian or Indian in particular, who have a different phenotype compared to western countries. He suggested a new cut-off value to define obesity as BMI $\geq 23$. This was similar to the new recommendations of the International Diabetes Federation to define obesity for Asian as BMI $\geq 25$.otherwise the findings are well understood, as the prevalence of the overweight group (BMI 25-29) IS 28.3\%, which is similar to the obese group of Ramachandran et al and Gupta et al.

Hypertension was defined as blood pressure more than 130/85mm of $\mathrm{Hg}$ for present study.45 (26.5\%) subjects had blood pressure higher than $130 / 85 \mathrm{~mm}$ of $\mathrm{Hg}$. Prevalence of hypertension among males $29.2 \%$ and among females is $23 \%$. This is lower than the prevalence of hypertension in Jaipur (Gupta et al) where it was $55 \%$. In Chennai, Ramachandran et al (2003) found that prevalence to be 39\%. This was obvious as the study population in Jaipur (Punjabi Bhatiya community) and the Chennai urban community had different lifestyle and dietary habits.

In the present study the prevalence of Impaired Glucose Tolerance is $24.1 \%$. The prevalence among males are $25 \%$ and among females are $23 \%$. Impaired fasting glucose value $\geq 110 \mathrm{mg} / \mathrm{dl}$ was taken as a cut off value. Reports from Chennai (Ramachandran et al) show prevalence is 5\% and report from Jaipur (Gupta et al) showed prevalence of $25 \%$ which was closer to the prevalence of Ranchi. Both of them used the same ATP III definition.

The prevalence of hypercholesterolemia (total cholesterol $\geq 250 \mathrm{mg} / \mathrm{dl}$ ) is $12.4 \%(21 / 170)$. Prevalence among men is $17.7 \%$ (17/96) and prevalence among women is 5.4 \%(4/74). Rajeev Gupta, Mukesh Sarna et al in their studies on north Indian Bhatiya community used cut off levels to define hypercholesterolemia as $\geq 200$ $\mathrm{mg} / \mathrm{dl}$. They found the prevalence among men is $33.2 \%$ and among women is $28.9 \%$. This fact is understood by the use of low cut off levels. 
After the analysis of data, the results showed that 35 out of a total 170 study subjects were diagnosed as cases of metabolic syndrome based on the NCEP ATP III diagnostic criteria. It is concluded that the prevalence (\%) of metabolic syndrome in Ranchi is $20.6 \%$. The results obtained by Ramachandran et al from Chennai (2003) showed that prevalence of metabolic syndrome in Chennai was $41 \%$. For diagnosis he used a waist circumference that is appropriate for Indians. Gupta et al (2003) reported that the prevalence of metabolic syndrome was $13 \%$ in Jaipur. He used the standard ATP III definition of obesity which was similar to that used in the present study. He studied the age group 20 and above. Another study from Chennai by Deepa et al (2002) reported a prevalence of $11.2 \%$. She used the European Group for the Study of Insulin Resistance (EGIR) criteria. Ranjita Mishra et al (2008) showed that the age adjusted prevalence of metabolic syndrome among Asian Indian immigrants in the US was $26.9 \%$ by the original NCEP ATP III criteria and $38.2 \%$ by the IDF criteria. Reports from the other countries have shown different rates of prevalence. According to Ford ES et al (2002), in the United States, the prevalence of metabolic syndrome increased from $24.1 \%$ in NHANES III to 27 $\%$ in NHANES 1999-2000.

\section{Conclusion}

The data obtained after the study shows that one out of every five adults in Ranchi is at an increased risk of developing diabetes and/or cardiovascular disease. Women are equally prone as men. Results show a shift toward a sedentary lifestyles, alcoholism and smoking.

\section{References}

[1]. Harrison's Internal Medicine $-17^{\text {th }}$ edition (Kasper, Braunwald, Fauci, Hauser, Longo, Jameson). Robert H Eckel, 2008 ; 236 : 1509 $-1510$.

[2]. Murray CJ, Lopez AD. Alternative projection of mortality and disability by cause 1990-2020. Global burden of disease study, Lancet 1997; 349: 1498-1504.

[3]. Stamler J, Vaccaro O, Neoton JD et al. Cardiovascular mortality for man screened in multiple risk factor intervention trial. Diabetes care 1993; 16: 434-444.

[4]. Patnaik UK. Indian scenario 2000: 49-53.

[5]. Gupta A, Gupta R, Sarna M, et al. prevalence of diabetes, impaired fasting glucose and insulin resistance syndrome in an urban Indian population. Diabetes Res Clin Pract $2003 ; 61: 69-76$

[6]. Gupta R, Sarna M, Thanvi J, Rastogi P, Kaul V, Gupta VP. Monilek Hospital and Research Center and Department of statistics and Home Science,University of Rajasthan,Jaipur. High prevalence of multiple coronary risk factors in Punjabi Bhatiya community: Jaipur Hear Watch - 3. Indian Heart Journal 2004; 56: 646-52

[7]. Kylin E. Zentralblatt Feur Innere Med 1923; $44: 105-127$.

[8]. ReavenGM Banting lecture1988.Role of insulin resistance in human diseases.diabetes 1988; 37:1595-607. 